\title{
RELATIONSHIP BETWEEN ORGANIZATIONAL DESIGN AND ORGANIZATIONAL LEARNING
}

\author{
PhD Borislav Kolarić, "Telecom Serbia"a.d. Belgrade, IJ Sremska Mitrovica, Serbia, \\ Mr Snežana Petrović, "Sveti Sava" primary school, Sremska Mitrovica
}

\begin{abstract}
Designing organizations in the present economic context should take into account organizational learning, as knowledge is considered to be one of the most important resources to the creation of sustainable competitive advantage. Companies can promote organizational learning by regulating mechanisms in its internal firm structure. An argument is put forward that firms can possess a learning strategy whose purpose is to optimize organizational mechanisms that promote organizational learning. This paper theoretically discusses how internal firm structures may be designed to optimize organizational learning.
\end{abstract}

Key words: organizational learning, organizational design

\section{Introduction}

Companies are seeking new ways to manage learning and competence in order to improve company performance and competitiveness. Organizations build up their competitive advantage by enlarging and enhancing their knowledge repository (Kogut \& Zander, 1992). Knowledge is a very special resource in the firm and knowledge management should respect its characteristics.

Organizational learning seams to develop competencies that are valued by the clients, hardly imitable, and, as a consequence, they contribute to the competitive advantage of the firm. Therefore, seeking ways to create new knowledge has become top priority of top management team. Researchers and practitioners alike appear to be reaching a consensus that organizational learning is a key strategic variable in order to cope with this shift.

Nonaka and colleagues (2000) define knowledge assets as firm-specific resources that are indispensable to create values for the firm. Since knowledge assets are crucial for organizations value creation, it cannot be denied that knowledge creation plays a critical role to organizations competence building. Therefore, organizations knowledge creation has always been top priority for top management team (von Krogh, 1998).

Organizational designs are seen as a set of consistent choices determined by contextual factors such as the organization's strategy and its environment (Burton \& Obel, 2004). Considering that the design of the organizational structure can affect performance and effectiveness through the functioning of the organization.

Organizational design is the process by which managers select and manage aspects of structure and culture so that an organization can achieve its goals. Organizational design helps a company deal with contingencies, achieve competitive advantage, manage diversity, and increase its efficiency and ability to innovate goods and services (Jones, 2007).

The concepts of organizational design is much more than who reports to whom and what types of jobs are contained in each department, it is the process that takes and molds the elements of the organizational structure's desires, demands, constraints, and choices. The process of implementing and choosing the appropriate structure design is contingent on the size of the organization, the operations, the information technology, its environment and the strategy it selects for growth and survival (Hunt, Osborn, \& Schermerhorn, 2005).

\section{Important of organizational learning}

Organizational learning is important to firms for several reasons. Learning allows a firm to renew itself, innovate (Freeman 1991), and possibly enjoy first mover advantages, for example in form of product designs, new organizational forms and/or faster product 
development rates than its competitors (Barney 1991).

Organizational learning occur when single individuals from their mental models and pictures of demands and environment, meets and detects a match or a mismatch with expectations and puts discoveries and evaluations of this in some form of accessible organizational memory.

Organizational learning in product innovation processes can be seen as diffusing best practice and sharing good as well as bad experiences (Cole, 1994). It also means using cross functional teams to increase effectiveness of product development efforts in order to reach better performance and competitiveness (Granath, 1991) In short, organizational learning requires that information is being shared, stored and used in a form convenient to all organization members (McKee, 1992).

Knowledge constitutes input into the learning process (Foray \& Lundvall,1996), that is, knowledge transfer in many cases is a means to generate new learning and among others an agent's existing knowledge stock, or the agents' absorptive capacity (Cohen \& Levinthal, 1990), is crucial for the ability to learn

Organizational learning may be visible in employees ultimately improving working processes and routines, or in employees for example creating new and better products or services. Both internal as well as external sources are input into the learning process (Pavitt, 1984).

Product innovation literatures distinguish three levels of organizational learning; incremental, discontinuous and organizational (Jones \& Hendry, 1992). Studies have shown that incremental organizational learning requires expertise focusing on operational levels and emphasizing integration of functions such as $R \& D$ and marketing. Incremental organizational learning can be seen as moving along an innovation curve to increased innovation efficiency and can be compared with single loop learning.

Discontinuous organizational learning has shown to require external high level skills, a playful creative internal climate and works best in small cross-functional teams. Discontinuous organizational learning can be seen as moving to a higher innovation curve with increased innovation effectiveness and can be compared with double loop learning.

Organizational learning involves learning how to innovate and examples have shown that it is generated through diffusing best practices, organizational memories, dealing with failures and organizational goals. Organizational learning can be seen as increasing both efficiency and effectiveness for incremental and discontinuous organizational learning and be compared with triple loop learning.

At each of these levels, learning must be managed and supported; it is not automatic (Kim, 1993).

\section{The role of organizational design}

Organizational design is the process of choosing and implementing a structural configuration (Osborn, Hunt, Jauch, 1984). The choice of an appropriate organizational design is contingent upon several factors, including the size of the firm, its operations and information technology, its environment, and the strategy it selects for growth and survival.

An effective organizational design also reflects powerful external forces as well as size and technological factors. Organizations, as open systems, need to receive inputs from the environment and in turn to sell outputs to their environment. Therefore, understanding the environment has become important (Osborn, Hunt, Jauch, 1984).

For many firms, size, technology, and environment provide too many challenges and opportunities. Organizational design scholars recommend that the design follow the strategy of the firm and that the strategy take advantage of a combination of advantages offered by size, technology, and the environment. Organizational strategy is the process of positioning the organization in its competitive environment and implementing actions to compete successfully (Osborn, Hunt, Jauch, 1984).

The study of linking strategy, organizational design, and firm performance has a long tradition in organizational analysis. In the 1960s, Alfred Chandler studied the evolution of major U.S. firms and concluded that structure follows 
from the strategy established predominantly by senior management. More recent work suggests that the formula for success is much more complicated (Chandler, 1977). A winning strategy is more likely when the firm recognizes both the importance of a focus and the unique skills and abilities within the firm. Forming a strategy is an interactive process. Senior managers select those systems goals they believe should define corporate success, form these goals into a vision, select a target position within the general and specific environments, and develop a design to accomplish the vision.

\section{Impact of organizational design for organization learning}

Management literature often addresses the necessity to have a concept of organizational change adequate to the turbulent and complex business environment. Management faces new patterns and combinations of old variables, as well as fundamental changes in the business logic and the assets used. Innovation, growth and productivity gains do not result from separating tasks and breaking the workflows of the knowledge-intensive operations, but rather from integrating and combining knowledge in order to jointly develop new ideas and solutions through problem solving processes. Being so, one of the main challenges management faces is to understand the roles of knowledge and learning to allow for organizational change and business success (Pawlowsky, 2003). The integration and combination of knowledge is a good way to design the organization for organizational learning, instead of separating tasks and breaking the workflows of the knowledge-intensive operations.

Resources like knowledge, learning capabilities, culture, teamwork and human capital, are presented as being the ones that most contribute to the firm sustained competitive advantage (Barney, 2001). Organizational capabilities emerge over time through organizational learning processes (Szulanski, 2003). As a consequence, the maintenance of the competitive advantage of the firm might depend upon past decisions and the way employees learn from past experiences (Alvarez \& Busenitz, 2001). Leveraging knowledge throughout the organization enlarges the knowledge base and develops a sharing culture that is a stimulus to organizational learning. These routines are a good way to design the organization for organizational learning, instead of promoting internal power distances associated to differences in knowledge stocks.

Organizational learning happens, by definition, in an organizational context, where the factors and conditions that model learning can be found (Antal et al., 2003). Learning involves organizational and individual capabilities (Teece et al., 1997). Learning and knowledge creation are activated, shaped and limited by the social constitution of the organizations where it occurs (Child \& Heavens, 2003).

The structure of the roles, interests and powers of the different organizational elements generates paradoxes and tensions that origin dynamics impacting on the learning processes. These dynamics associated to the social identification of each organizational element uncover strong emotions. As a consequence, sometimes organizations do not learn from past relevant experiences, either successes or failures (Antal et al., 2003). Successes and failures may, however, constitute factors that condition organizational learning (Starbuck \& Hedberg, 2003) or the employees' emotions (Scherer and Tran, 2003). Considering the social dimension of learning is a good way to design the organization for organizational learning, instead of considering that learning is only individual and is not influenced by social elements. Organizational structure can be used to strengthen exploration by undermining the effectiveness of exploitation, like failures to recall past lessons, to implement past solutions, to communicate about current problems, all contribute to inefficiency in refining current practice.

In the organizational structure there is many professionals who have very rich and different past organizational positions. Many come from information technology departments, human resources departments, or intellectual property areas, but they all have a strategic and multifunctional vision of the organization, that is superior to the specific area of specialization they were in.

Albers and Jerke (2004) present, in a much systematized way, the organizational factors that have significant impact in knowledge management: 
1. The organizational culture (the values reflected in shared behavior and shared attitudes)

2. The organizational leadership (the actions, the words, the ethics and the examples that leaders set).

3. The organizational interest in organizational learning (the priority given to and the efforts made in support of the management of organizational learning)

4. The organizational knowledge processes (information and knowledge sharing mechanisms, tacit and explicit knowledge exchange, and organizational communication).

5. The organizational structure (the hierarchy, the groups, the geographic location and the work space distribution).

6. The organizational technological infrastructure (the hardware and software components used in the communication and in the collaboration between organizational members, and used in the storage, in the transfer, in the location, in the creation and in the integration of knowledge).

The existence of professionals in the firm's structure is a good way to design the organization for organizational learning, instead of considering that learning is an individual aspect of each employee which cannot be managed by the firm.

\section{Conclusion}

Nadler and Tushman (1997) observe that the only real, sustainable source of competitive advantage lies in organization architecture - the way in which it structures and coordinates its people and processes in order to maximize its unique capability over long haul. Organizational learning is important to firms. It is a potential source of competitive advantage as it may lead to various types of process or product innovations.

Individual learning is necessary but not sufficient to produce organizational learning. A prerequisite for organizational learning is that knowledge, experience and best practice is accessible to others beyond the individuals, and it must be subject to application, change and adaptation by others in the organization. Through the collective design process, a learning process in itself, new issues and combinations of different aspects have been brought to discussion.

Managing of organizational design is an interactive process that can support organizational learning and that must be adapted to strategy and the specific culture in which the results will be used. The integration and combination of knowledge is a good way to design the organization for organizational learning, instead of separating tasks and breaking the workflows of the knowledgeintensive operations.

Organizational capabilities emerge over time through organizational learning processes. Recognizing that individuals are able to learn from past experiences and that they aren't totally rational in their decision-making processes is a good way to design the organization for organizational learning, instead of considering employees are perfectly rational and able to respond optimally and instantaneously to changing conditions. The existence of professionals in the firm's structure is a good way to design the organization for organizational learning, instead of considering that learning is an individual aspect of each employee which cannot be managed by the firm.

\section{REFERENCES}

1. Albers, J. \& Jerke, D. (2004). Organizational Factors for an Effective Knowledge Management Environment, In Bart, Bontis and Head (Eds.)

2. Alvarez, S. \& Busenitz, L. (2001). The entrepreneurship of resource-based theory, Journal of Management, 27, pp. 755-775.

3. Antal, A., Dierkes, M., Child, J. \& Nonaka, I. (2003). Handbook of Organizational Learning \& Knowledge. Oxford: Oxford University Press, pp. 1-13.

4. Barney, J. (1991). Firm Resources and Sustained Competitive Advantage, The Journal of Management, 17, pp. 99-120.

5. Barney, J. (2001) Is the resource-based "view" a useful perspective for strategic management research? Yes. Academy of Management Review, 26 (1), pp. 41-56.

6. Burton, R. \& Obel, B. (2004) Strategic Organizational Diagnosis and Design: The Dynamics of Fit - Third Edition, Dordrecht, 
The Netherlands: Klumer Academic Publishers.

7. Chandler, A.D. (19779, The Visible Hand: The Managerial Revolution in America.Cambridge, MA: Belknap.

8. Child, J. \& Heavens, S. (2003). The Social Constituition of Organizations and its Implications for Organizational Learning, Handbook of Organizational Learning \& Knowledge. Oxford: Oxford University Press, pp. 308-326.

9. Cohen, W. M. \& Levinthal, D. (1990). Absorptive capacity: A new perspective on learning and innovation, Administrative Science Quarterly, 35/1, pp. 128-152.

10. Cole, R. (1994). A comparative Perspective on Individual and Organizational Learning in Western and Japanese Industry. Paper presented at the conference "Towards Learning in Working Life" 17-18 November, Stockholm, Sweden.

11. Foray, D. \& Lundvall B.A. (1996). The knowledge-based economy: From the economics of knowledge to the learning economy. Aalborg University, Institut for Erhvervsstudier.

12. Freeman, C. (1991). The nature of innovation and the evolution of the productive system, in Technology and Productivity. The Challenge for Economic Policy, Paris: OECD.

13. Granath, J. ̊. (1991). Architecture, technology and Human Factors: Design in a Socio-Technical Context. Ph.D. Diss. Gothenburg: Industrial Architecture and Planning, Chalmers University of Technology.

14. Jones, A.M. \& C. Hendry. (1992). The Learning Organization: A review of literature and practice. London: HRDP.

15. Jones, G. R. (2007). Organizational Theory, Design, and Change (5th ed.). New Jersey: Pearson Education, Inc.

16. Kim, D.H. (1993). The link between individual and organizational learning. Sloan Management Review, vol 35, pp. 3750.

17. Kogut, B., \& Zander, U. (1992). Knowledge of the firm, combinative capabilities, and the replication of technology. Organization Science, 3 (3), pp. 383-397.
18. McKee, D. (1992). An Organizational Learning Approach to Product Innovation. The Journal of Product Innovation Management, pp. 232-245. New York: Elsevier Science Publ.

19. Nadler, D. A. \& Tushman, M. L. (1997). Implementing New Designs: Managing Organizational Change. Managing Strategic Innovation and Change: A Collection of Readings. Oxford University Press,New York.

20. Nonaka, I., Toyama, R., \& Konno, N. (2000). SECI, ba and leadership: a unified model of dynamic knowledge creation. Long Range Planning, 33 (1), 5-34.

21. Osborn, R. N. Hunt J. G., \& Jauch L. (1984). Organization Theory: Integrated Text and Cases Melbourne, FL: Krieger.

22. Pavitt, K. (1984). Sectoral Patterns of Technical Change: Towards a Taxonomy and a Theory, Research Policy, Vol. 13, pp. 343-373.

23. Pawlowsky, P. (2003). The Treatment of Organizational Learning in Management Science, Handbook of Organizational Learning \& Knowledge. Oxford: Oxford University Press, pp. 62-88.

24. Scherer, K. and Tran, V. (2003). Effects of Emotion on the Process of Organizational Learning. Handbook of Organizational Learning \& Knowledge. Oxford: Oxford University Press, pp. 369-392.

25. Schermerhorn, J.R., Hunt, J.G. \& Osborn, R.N. (2005). Organizational Behaviour $9^{\text {th }}$ edition. John Wiley \& Sons, Inc.

26. Starbuck, W. \& Hedberg, B. (2003). How Organizations Learn from Success and Failure, Handbook of Organizational Learning \& Knowledge. Oxford: Oxford University Press, pp. 327-350.

27. Szulanski, G. (2003). Sticky Knowledge barriers to knowing in the firm. London: Sage Publicatios Ltd.

28. Teece, D., Pisano, G. \& Shuen, A. (1997). Dynamic capabilities and strategic management, Strategic Management Journal, 18 (7), pp. 509-534.

29. Von Krogh, G. (1998). Care in Knowledge Creation. California Management Review, 40(3): 133-153 